\title{
Analysis of the vapor-oxygen oxidizer in the synthesis gas production from solid fuel
}

\author{
Elena S. Popova ${ }^{1}$, and Alexander N. Subbotin ${ }^{1, *}$ \\ ${ }^{1}$ National Research Tomsk Polytechnic University, 634050 Tomsk, Russia
}

\begin{abstract}
A universal method of processing low-grade coals, as well as energy waste, is their gasification. A mathematical model of the conversion of coke, placed in a cylindrical capsule, through which a steam-oxygen blow is carried out, is considered. The determining parameter is the proportion of oxygen in the oxidizer. The values of the oxygen concentration in a steam-oxygen oxidizer are found to produce a synthesis gas with a predetermined percentage of combustible components.
\end{abstract}

\section{Introduction}

A huge amount of waste from coal mining and coking (slimes and stubble) have no application. The combustion of coal adversely affects the environment. In this connection, interest in alternative methods of processing is growing. Special attention is now being paid to the gasification of solid fuels. There is an opportunity to process low-grade coal, from power inputs with a significant reduction in emissions to the atmosphere [1]. The resulting synthesis gas is applicable both in power engineering and in the chemical industry. In particular, a sufficiently large amount of hydrogen is required in the production of ammonia and methanol [2]. Gasification is possible with different modes of solid fuel conversion. As reacting agents, steam or oxygen (or a mixture thereof), air may act. Involving oxygen in the process of gasification makes it possible to accelerate and increase the stability of reactions occurring during the conversion [1]. Currently, mathematical modeling of various physical processes is widely used [3]-[6]. Consider the mathematical model of the solid fuel conversion process.

\section{Physical and mathematical model}

The investigated object is a cylindrical capsule filled with coke. Fuel is ignited due to the steam-oxygen mixture heated to a certain temperature. In the modeling of fuel conversion, the following chemical reactions are considered:

$$
\begin{gathered}
\mathrm{C}+\mathrm{H}_{2} \mathrm{O}=\mathrm{CO}+\mathrm{H}_{2}-130,5 \mathrm{~kJ} / \mathrm{mol}, \\
\mathrm{C}+\mathrm{CO}_{2}=2 \mathrm{CO}-175,5 \mathrm{~kJ} / \mathrm{mol}, \\
\mathrm{C}+\mathrm{O}_{2}=\mathrm{CO}_{2}+395 \mathrm{~kJ} / \mathrm{mol}, \\
2 \mathrm{C}+\mathrm{O}_{2}=2 \mathrm{CO}+219 \mathrm{~kJ} / \mathrm{mol},
\end{gathered}
$$

\footnotetext{
*Corresponding author: subbot@tpu.ru
} 


$$
\begin{gathered}
2 \mathrm{H}_{2}+\mathrm{O}_{2}=2 \mathrm{H}_{2} \mathrm{O}+219 \mathrm{~kJ} / \mathrm{mol} \\
2 \mathrm{CO}+\mathrm{O}_{2}=2 \mathrm{CO}_{2}+571 \mathrm{~kJ} / \mathrm{mol} \\
\mathrm{CO}+\mathrm{H}_{2} \mathrm{O}=\mathrm{CO}_{2}+\mathrm{H}_{2}+40,4 \mathrm{~kJ} / \mathrm{mol}
\end{gathered}
$$

The task is to determine the composition of the synthesis gas during the conversion of coke, the analysis of its composition, depending on the quantitative oxygen content in the steam-oxygen oxidizer. The research was carried out using a mathematical model. According to [3], a system of equations is developed:

- $\quad$ conservation of coke mass

$$
\rho_{3} \cdot \frac{\partial \phi_{3}}{\partial \tau}=-R_{C}, \quad R_{C}=R_{C 1}+R_{C 2}+R_{C 3}+R_{C 4}
$$

- $\quad$ continuity of the gas phase

$$
\frac{\partial \rho_{5} \phi_{5}}{\partial \tau}+\frac{\partial \rho_{5} \phi_{5} v}{\partial z}=R_{C}
$$

- continuity $\alpha$-of the gas phase component

$$
\frac{\partial\left(\rho_{5} \varphi_{5} c_{\alpha}\right)}{\partial \tau}+v \frac{\partial\left(\rho_{5} \varphi_{5} c_{\alpha}\right)}{\partial z}=\frac{\partial}{\partial z}\left(\rho_{5} \varphi_{5} D_{\alpha} \frac{\partial c_{\alpha}}{\partial z}\right)+R_{5 \alpha}+R_{S \alpha}, \alpha=\overline{1,4}
$$

here parameter with an index $\alpha=1$ corresponds to the oxygen $\left(\mathrm{O}_{2}\right), \alpha=2-\mathrm{CO}$, $\alpha=3-\mathrm{CO}_{2}, \alpha=4-\mathrm{H}_{2}, \alpha=5-\mathrm{H}_{2} \mathrm{O}$;

- conservation of energy of the gas phase

$$
\begin{aligned}
& \rho_{5} \varphi_{5} c_{P 5}\left(\frac{\partial T}{\partial \tau}+v \cdot \frac{\partial T}{\partial z}\right)=\frac{\partial}{\partial z}\left(\left(\lambda_{5}+\lambda_{R}\right) \varphi_{5} \frac{\partial T}{\partial z}\right)-A_{s}\left(T-T_{S}\right) \\
& +q_{C O}^{1} R_{C O}^{1}+q_{C O}^{2} R_{C O}^{2}+q_{H_{2}} R_{H_{2}}-\frac{2}{r_{o}} \alpha_{1} \varphi_{5}\left(T-T_{S}\right) ;
\end{aligned}
$$

- conservation of energy of the condensed phase

$$
\begin{aligned}
& \sum_{i=3}^{4} \rho_{i} \varphi_{i} c_{p_{i}} \frac{\partial T_{S}}{\partial \tau}=\frac{\partial}{\partial z}\left(\lambda_{S} \frac{\partial T_{S}}{\partial z}\right)+q_{C 1} R_{C 1}+q_{C 2} R_{C 2}-q_{C 3} R_{C 3}-q_{C 4} R_{C 4}+ \\
& A_{S}\left(T-T_{S}\right)+\frac{2 \cdot r_{1}}{r_{0}^{2}} \alpha_{2}\left(T_{S}-T_{E}\right)+q_{R} ;
\end{aligned}
$$

- gas motion in the pores (in the form of a quadratic filtration law) and the equation of state

$$
v=\frac{k}{\mu+k \cdot \beta \cdot \rho_{5}|V|} \cdot \frac{\partial p}{\partial z}, \quad p=\frac{\rho_{5} \cdot R \cdot T}{M_{5}} .
$$

The system of equations (1) - (6) was solved under the boundary conditions:

$$
\tau=0: \quad \varphi_{i}=\varphi_{i H}, i=\overline{3,4} ; \quad c_{\alpha}=c_{\alpha H}, \alpha=\overline{1,4}, \quad T=T_{S}=T_{H}, \quad p=p_{H}
$$




$$
\begin{array}{ll}
\mathrm{z}=0: & T=T_{G}, \quad(p v)_{w}=\text { const }, \quad \lambda_{S} \cdot \frac{\partial T_{S}}{\partial z}=\alpha_{1} \cdot\left(T_{S}-T_{G}\right), \quad c_{\alpha}=c_{\alpha G}, \\
\mathrm{z}=\mathrm{h}: & \frac{\partial c_{\alpha}}{\partial z}=\frac{\partial T}{\partial z}=0, \quad p=p_{H}, \quad \lambda_{S} \frac{\partial T_{S}}{\partial z}=0 .
\end{array}
$$

In the equations (2) - (7) the following notation is introduced: $c_{p_{5}}=\sum_{\alpha=1}^{5} c_{p_{\alpha}} c_{\alpha}$, $\lambda_{S}=\sum_{i=3}^{4} \lambda_{i} \varphi_{i}, \quad \lambda_{R}=\frac{16 \sigma T^{3}}{s}, \quad M_{5}=1 / \sum_{\alpha=1}^{7} \frac{c_{\alpha}}{M_{4 \alpha}}, \quad R_{\mathrm{C} 1}=s \rho_{5} \varphi_{5} c_{7} k_{S 1} \varphi_{3 .} \exp \left(\frac{-E_{\mathrm{C} 1}}{R \cdot T_{S}}\right)$, $R_{\mathrm{CO}}^{2}=k_{\mathrm{CO}}^{2}\left(c_{1} M / M_{51}\right)^{0.25}\left(c_{2} M / M_{52}\right) \cdot T^{-2.25} \exp \left(\frac{-E_{\mathrm{CO}}^{2}}{R \cdot T}\right), \quad R_{\mathrm{C} 2}=s \rho_{5} \varphi_{5} c_{3} k_{S 2} \varphi_{3} \exp \left(\frac{-E_{\mathrm{C} 2}}{R \cdot T_{S}}\right)$, $R_{\mathrm{C} 3}=s \rho_{5} \varphi_{5} c_{1} k_{S 3} \varphi_{3} \exp \left(\frac{-E_{\mathrm{C} 3}}{R \cdot T_{S}}\right), \quad R_{\mathrm{CO}}^{1}=k_{\mathrm{CO}}^{1} c_{2} c_{7} \exp \left(\frac{-E_{\mathrm{CO}}^{1}}{R \cdot T}\right), \quad R_{\mathrm{H}_{2}}=k_{\mathrm{H}_{2}} c_{1} c_{4} \cdot \exp \left(\frac{-E_{\mathrm{H}_{2}}}{R \cdot T}\right)$, $R_{52}=\gamma_{5} R_{C 1}+\gamma_{6} R_{C 2}+\gamma_{7} R_{C 4}, \quad R_{54}=\gamma_{13} R_{\mathrm{C} 1}+\gamma_{14} R_{\mathrm{CO}}^{1}-\gamma_{15} R_{\mathrm{H}_{2}}, \quad R_{57}=\gamma_{16} R_{\mathrm{H}_{2}}-\gamma_{17} R_{\mathrm{C} 1}-\gamma_{18} R_{\mathrm{CO}}^{1}$, $R_{51}=-\left(\gamma_{1} R_{\mathrm{C} 2}+\gamma_{2} R_{\mathrm{C} 3}+\gamma_{3} R_{\mathrm{H}_{2}}+\gamma_{4} R_{\mathrm{CO}}^{2}\right), \quad R_{53}=\gamma_{8} R_{\mathrm{C} 3}-\gamma_{10} R_{\mathrm{C} 2}+\gamma_{11} R_{\mathrm{CO}}^{1}+\gamma_{12} R_{\mathrm{CO}}^{2}$, $R_{\mathrm{C} 4}=s \rho_{5} \varphi_{5} c_{1} k_{S 4} \varphi_{3} \exp \left(\frac{-E_{\mathrm{C} 4}}{R \cdot T_{S}}\right)$. All other notations coincide with the notation introduced in [5].

\section{Analysis of numerical results}

According to [6], during steam gasification of solid fuel, the composition of the synthesis gas is affected by the temperature of the oxidizer, the specific surface area of the pores and the porosity. In [7], the influence of the oxygen concentration in the vapor-oxygen oxidant on the percentage composition of the synthesized gas formed is considered. As shown by numerical calculations, an important parameter in this case is the fraction of oxygen in the oxidant. Table 1 shows the studies on the composition of the resulting synthesis gas during the conversion of coke in a heated vapor-oxygen oxidizer with various mass concentrations of oxygen in it.

The synthesis gas compositions shown in Table 1 were obtained at: $T_{\mathrm{e}}=873 \mathrm{~K}, T_{\mathrm{e}}$ is the temperature of the oxidant supplied to the capsule; $\varphi_{3 \mathrm{H}}=0.8, \varphi_{3 \mathrm{H}}$ - initial volume fraction of coke placed in the capsule $S_{*}=5 \cdot 10^{4}, 1 / \mathrm{m}, S_{*}$ is the initial specific surface area of the pores.

Table 1. Composition of synthesis gas and temperature of gas and condensed phases during steam-

\begin{tabular}{|c|c|c|c|c|c|c|c|c|c|c|}
\hline \multicolumn{2}{|c|}{ Concentration $\mathrm{O}_{2}$} & 0.04 & 0.06 & 0.08 & 0.1 & 0.15 & 0.2 & 0.25 & 0.3 & 0.35 \\
\hline \multirow{5}{*}{$\begin{array}{c}\text { Volumetric } \\
\text { composition } \\
\text { synthesis gas } \\
\%\end{array}$} & $\mathrm{CO}$ & 8.0 & 14.3 & 22.2 & 33.0 & 55.4 & 60.6 & 64.1 & 67.0 & 70.2 \\
\hline & $\mathrm{H}_{2}$ & 13.6 & 23.6 & 33.7 & 42.9 & 44.0 & 39.4 & 35.9 & 33.0 & 29.8 \\
\hline & $\mathrm{O}_{2}$ & - & - & - & - & - & - & - & - & - \\
\hline & $\mathrm{CO}_{2}$ & 2.9 & 4.4 & 5.5 & 5.2 & 0.4 & - & - & - & - \\
\hline & $\mathrm{H}_{2} \mathrm{O}$ & 75.5 & 57.7 & 38.6 & 18.9 & 0.2 & - & - & - & - \\
\hline \multirow{2}{*}{$\begin{array}{l}\text { Maximum } \\
\text { temperature, } \mathrm{K}\end{array}$} & gas & 910 & 950 & 996 & 1040 & 1175 & 1327 & 1405 & 1478 & 1510 \\
\hline & coke & 918 & 964 & 1018 & 1067 & 1248 & 1415 & 1510 & 1621 & 1703 \\
\hline
\end{tabular}
gasification of coke.

From the analysis of the data presented in Table 1, it follows that at a mass concentration of oxygen up to 0.1 , the volume fraction of the combustible gas is about 22 to 
$75 \%$, there is a lot of water vapor, the volume fraction of which is approximately 75 $19 \%$. The products of gasification contain a small amount of carbon dioxide. Under a mass concentration of oxygen in a steam oxygen oxidizer of more than 0.15 , a synthesis gas consisting of hydrogen and carbon monoxide is produced.

The lower lines of the table show the maximum values of the temperature of synthesis gas and coke in the combustion zone. Wesee that when the oxygen concentration in the oxidant is less than 0.15 , the temperature in the conversion region is low, does not exceed $1100 \mathrm{~K}$. Therefore, the process proceeds slowly and the gasification products contain a lot of water vapor. As follows from the table, with an increase in the oxygen concentration, the temperature of both the gas and condensed phases increases.

With the increase in the oxygen concentration to 0.15 , the volume content of carbon dioxide and hydrogen in the synthesis gas increases. With a mass concentration of oxygen in the oxidizer of more than 0.15 in the synthesis gas, the volume fraction of hydrogen begins to decrease, and carbon dioxide continues to grow.

Table 2. Characteristics of synthesis gas for steam-oxygen gasification of coke $\left(\varphi_{3 \mathrm{H}}=0.5, S_{*}=5 \cdot 10^{3}\right.$, $1 / \mathrm{m})$.

\begin{tabular}{|c|c|c|c|c|c|c|c|c|c|}
\hline \multicolumn{2}{|c|}{ Concentration $\mathrm{O}_{2}$} & 0.1 & 0.15 & 0.2 & 0.25 & 0.3 & 0.35 & 0.4 & 0.45 \\
\hline \multirow{4}{*}{$\begin{array}{c}\text { Volumetric } \\
\text { composition } \\
\text { synthesis gas, } \\
\%\end{array}$} & $\mathrm{CO}_{2}$ & 2.7 & 7.0 & 17.1 & 33.7 & 46.9 & 55.7 & 61.0 & 64.6 \\
\cline { 2 - 11 } & $\mathrm{O}_{2}$ & 0.2 & 36.4 & 49.0 & 49.0 & 44.0 & 39.9 & 36.8 & 34.3 \\
\cline { 2 - 11 } & $\mathrm{CO}_{2}$ & 12.0 & 20.3 & 22.8 & 16.1 & 9.1 & 4.4 & 2.2 & 1.1 \\
\cline { 2 - 11 } & $\mathrm{H}_{2} \mathrm{O}$ & 66.1 & 36.2 & 11.0 & 1.2 & - & - & - & - \\
\hline $\begin{array}{c}\text { Maximum } \\
\text { temperature, } \mathrm{K}\end{array}$ & gas & 934 & 979 & 1015 & 1051 & 1085 & 1122 & 1153 & 1186 \\
\cline { 2 - 10 } & coke & 984 & 1065 & 1149 & 1245 & 1346 & 1482 & 1604 & 1722 \\
\hline
\end{tabular}

Table 2 shows the characteristics of the synthesis gas for various concentrations of oxygen in the oxidant during the conversion of coke to a larger fraction. Analyzing the characteristics of the synthesis gas obtained in the two tables, we conclude that when the coke is converted into a larger fraction, more oxygen must be added to the water vapor. In particular, in order to obtain a synthesis gas with substantially the same characteristics, in the first case the oxygen concentration in the oxidant should be 0.15 and 0.25 , and for the larger fraction coke, respectively, 0.35 and 0.45 .

Table 3. Characteristics of synthesis gas with decreasing oxidizer temperature $\left(S_{*}=5 \cdot 103.1 / \mathrm{m}\right)$.

\begin{tabular}{|c|c|c|c|c|c|c|c|}
\hline \multirow{2}{*}{\multicolumn{2}{|c|}{\begin{tabular}{|c|} 
Coke volume fraction \\
Concentration of $\mathrm{O}_{2}(\mathrm{C} 1)$ \\
\end{tabular}}} & \multicolumn{2}{|c|}{$\varphi_{3 \mathrm{H}}=0,2$} & \multicolumn{2}{|c|}{$\varphi_{3 \mathrm{H}}=0,5$} & \multicolumn{2}{|c|}{$\varphi_{3 \mathrm{H}}=0,8$} \\
\hline & & \multicolumn{2}{|c|}{0.40} & \multicolumn{2}{|c|}{0.35} & \multicolumn{2}{|c|}{0.25} \\
\hline \multicolumn{2}{|c|}{ Oxidizing agent temperature } & $873 \mathrm{~K}$ & $373 \mathrm{~K}$ & $873 \mathrm{~K}$ & $373 \mathrm{~K}$ & $873 \mathrm{~K}$ & $373 \mathrm{~K}$ \\
\hline \multirow{5}{*}{$\begin{array}{c}\text { Volume synthesis of } \\
\text { gas, } \%\end{array}$} & $\mathrm{CO}$ & 59.3 & 56.1 & 55.7 & 53.6 & 58.8 & 58.2 \\
\hline & $\mathrm{H}_{2}$ & 36.6 & 37.3 & 39.9 & 40.3 & 39.9 & 40.2 \\
\hline & $\mathrm{O}_{2}$ & - & - & - & - & - & \\
\hline & $\mathrm{CO}_{2}$ & 4.1 & 6.6 & 4.4 & 6.1 & 1.3 & 1.6 \\
\hline & $\mathrm{H}_{2} \mathrm{O}$ & - & - & - & - & - & - \\
\hline \multirow{2}{*}{$\begin{array}{c}\text { Maximum } \\
\text { temperature, } \mathrm{K}\end{array}$} & gas & 1235 & 1207 & 1122 & 1073 & 1066 & 1022 \\
\hline & coke & 1806 & 1759 & 1482 & 1461 & 1394 & 1363 \\
\hline
\end{tabular}

Table 3 presents numerical calculations for different porosities and initial concentrations of oxygen in a steam-oxygen oxidizer. The gas composition and maximum temperatures in the combustion zone, given in the first columns of the table for different values of $\varphi_{3 \mathrm{H}}($ volume fraction of coke), were obtained at the temperature of a steam oxygen oxidizer 
of $873 \mathrm{~K}$. The second columns contain the same values of the synthesis gas parameters when the oxidant temperature decreases after ignition up to $373 \mathrm{~K}$.

Analyzing the data given in Table 3, we come to the conclusion that after the ignition of the fuel, the conversion process can be carried out at a lower oxidant temperature. The composition of the resulting combustible gas varies slightly. The change in the composition of the resulting synthesis gas at different grinds (large, medium fine) is shown in Table 4.

Table 4. Dependence of characteristics of synthesis gas on the specific surface of the pores $\left(S_{*}\right)$ at two initial porosity and oxygen concentrations of $\mathrm{C}_{1}=0.35$.

\begin{tabular}{|c|c|c|c|c|c|c|c|}
\hline \multicolumn{2}{|c|}{ Initial porosity, $\varphi_{5 \mathrm{H}}$} & \multicolumn{3}{c|}{0,8} & \multicolumn{3}{c|}{0,5} \\
\hline \multicolumn{2}{|c|}{$S_{*}, 1 / \mathrm{m}$} & $5 \cdot 10^{2}$ & $5 \cdot 10^{3}$ & $5 \cdot 10^{4}$ & $5 \cdot 10^{2}$ & $5 \cdot 10^{3}$ & $5 \cdot 10^{4}$ \\
\hline \multirow{4}{*}{$\begin{array}{c}\text { Volumetric } \\
\text { synthesis of } \\
\text { gas, } \%\end{array}$} & $\mathrm{CO}$ & 30.3 & 52.6 & 61.8 & 34.6 & 55.7 & 61.1 \\
\cline { 2 - 9 } & $\mathrm{H}_{2}$ & 43.4 & 39.9 & 38.0 & 43.1 & 39.9 & 38.9 \\
\cline { 2 - 8 } & $\mathrm{O}_{2}$ & 3.4 & - & - & 1.4 & - & - \\
\cline { 2 - 8 } & $\mathrm{CO}_{2}$ & 21.2 & 7.5 & 0.2 & 19.2 & 4.4 & - \\
\cline { 2 - 8 } & $\mathrm{H}_{2} \mathrm{O}$ & 1.7 & - & - & 1.7 & - & - \\
\hline \multirow{2}{*}{$\begin{array}{c}\text { Maximum } \\
\text { temperature, } \mathrm{K}\end{array}$} & gas & 887 & 1199 & 1425 & 886 & 1122 & 1342 \\
\cline { 2 - 8 } & coke & 1648 & 1592 & 1551 & 1517 & 1482 & 1457 \\
\hline
\end{tabular}

Analyzing the data of Table 4, it can be argued that when the fraction of converted fuel decreases, the composition of the gas and the temperature of the process change. The temperature difference between the gas and solid phases decreases with decreasing fuel fraction.

\section{Conclusions}

The analysis of the synthesized gas compositions obtained allows us to state that:

a) the oxygen concentration in the steam-oxygen oxidant significantly changes the composition of the gasification products, therefore, it is always possible to select the oxidant necessary to produce a combustible gas of a certain composition;

b) the smaller the fraction of convertible solid fuel, the less oxygen must be added to the oxidizer during conversion;

c) it is always possible to select the composition of a steam oxygen oxidizer, in which a synthesis gas consisting of carbon monoxide and hydrogen is obtained.

\section{References}

1. B. I. Bondarenko, E. A. Khadzhinov, Dnepropetrovsk: NPVK "Triacon" 3 (2011)

2. B. K. Nefedov, Catalysis in the chemical and petrochemical industry 4 (2008)

3. P. S. Gergelizhiu, S. A. Khaustov, R. B. Tabakaev, P. Y. Novoseltsev, A. V. Kazakov, A.S. Zavorin, Proc. of 2014 Int. Conf. on MEACS (2014)

4. S. A. Khaustov, Y. A. Belousova, K. V. Buvakov, A. Y. Dolgih, R. N. Kulesh, 11th International Forum on Strategic Technology (IFOST - 2016) Proceedings 2 (2016)

5. A. N. Subbotin, Izvestiya Tomsk Polytechnic University 4 (2008)

6. R. N. Kulesh, A. S. Mazanik, A. N. Subbotin, Izvestiya Tomsk Polytechnic University. Technics and technologies in power engineering 4 (2014)

7. R. N. Aryukov, A. N. Subbotin, Collection of materials II All-Russian youth scientificpractical conference "Introduction to energy" (2016) [in Russian] 